\title{
Machine Components Modal Simulation Design based on the Finite Element Modeling
}

\author{
Asmamaw Mekonnen Yihunie ${ }^{1}$, Deng San Peng ${ }^{2}$, Jiang Yongxiang ${ }^{3}$, Wu Qing ${ }^{4}$, Yan Rui Jie ${ }^{5}$ \\ ${ }^{1}$ Mechanical manufacture and Automation Engineering, Tianjin University of Technology and Education,Tianjin, China \\ ${ }^{2}$ Professor, College of Mechanical Engineering Tianjin University of Technology and Education, Tianjin 300222, China \\ ${ }^{3}$ Professor, College of Mechanical Engineering Tianjin University of Technology and Education, Tianjin300222, China \\ ${ }^{4}$ Human Technician College of Industry and commerce, Industrial Automation Department \\ ${ }^{5}$ Human Technician college of Industry and Commerce, Mechanical Department
}

\begin{abstract}
Based on the finite element method, taking Computer numerical control (CNC) machine tool spindle as the research object, using the finite element analysis soft ware ANSYS work bench, the result of the modal analysis is used to take structural dynamic optimization. Firstly, ANSYS Work bench is used to spindle modal calculation, analysis the natural frequencies and modal shapes; further, weak points on the machine structure are analyzed and optimization methods are pointed out. Finally, in order to optimize the weak points of the object, considering the increment of natural frequency of the spindle as the optimization objective, the structural dynamic modification optimizes is taken.
\end{abstract}

Keywords: ANSYS; modal analysis; dynamic optimization; structural modification

\section{Introduction}

The vibration in the machining process is a phenomenon dynamically unstable. These instabilities, often generative, are generated by many factors such as the work piece flexibility the properties materials of the tools, the machine rigidity, tool geometry(approaching angle, rake angle, etc) and the cutting tool edge radius, the nominal cutting conditions such as tool wear, feed rate and depth of cut, etc. Spindle system is one of the key components of a machine tool, since its performance directly affect the machining accuracy and the cutting ability of the whole machine. Thus, in order to avoid unacceptable degradation of machining accuracy and surface processing quality, Vibrations should be minimized as far as possible. Along with the constant improvement of the accuracy of CNC machine tool, dynamic characteristics analysis of CNC machine and structural dynamic optimization will effectively improve the vibration performance of the machine.

In this paper, based on the finite element method to CNC machine tool spindle for the study, using finite element analysis ANSYS Work bench soft ware, according to the result of modal analysis structural dynamic optimization is taken. First, the finite element analysis ANSYS Work bench soft ware is used to calculate spindle modal analysis of natural frequencies and mode shapes; then based on the analysis of machine tool structural weaknesses, optimization methods are put forward. Finally the weak spot as optimization objective, in order to improve the spindle natural frequency as the optimization goal, optimization of structural dynamic modification design was carried out.

\section{Modal Analysis of Machine Tool Spindle}

Modal analysis is the study of the dynamic properties of structures under vibration excitation. A modal analysis, or more accurately experimental modal analysis, is the field of measuring and analyzing the dynamic response of structure when excited by an input. Using ANSYS Work bench soft ware for spindle structure modal analysis, to understand the dynamic characteristics of the spindle, is the first step in structural optimization design of the spindle.

\subsection{Modeling}

Modeling is the process of producing a model; a model is a presentation of the construction and working of some system of interest. A model is similar to but simpler than the system it represents. One purpose of model is to enable the analyst to predict the effect of changes to the system. Based on Pro/E to establish the three-dimension of the spindle, imported through IGES format into ANSYS Workbench, the spindle mesh model is shown in figure 1.

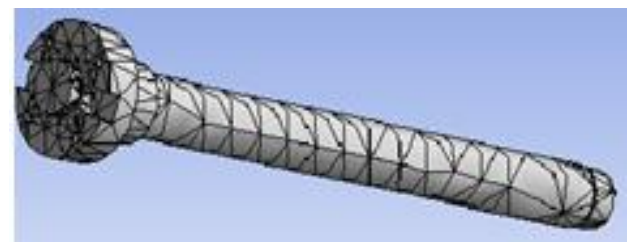

Figure 1: Spindle finite element mesh model

\subsection{Model analysis and calculation results}

Using the spindle unconstrained freestate, to solve the modal parameters; the natural frequency of the spindle is as shown table 1.

Table 1: Spindle Natural Frequency

\begin{tabular}{|c|c|c|c|c|c|c|}
\hline$F$ & 1 & 2 & 3 & 4 & 5 & 6 \\
\hline spindle & 724 & 789 & 2053 & 2201 & 2603 & 3957 \\
\hline
\end{tabular}




\section{International Journal of Science and Research (IJSR) \\ ISSN (Online): 2319-7064 \\ Index Copernicus Value (2013): 6.14 | Impact Factor (2014): 5.611}

As the spindle is a symmetrical body, the first-order natural frequency and the second-order natural frequency values are less than the third-order natural frequency and the fourth order natural frequency. The spindle natural frequency order 1-6 vibration mode is shown in figure- 2 .

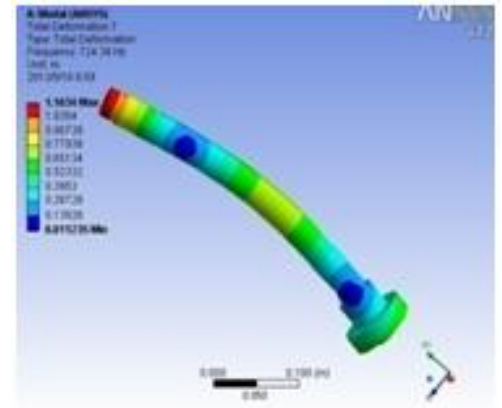

(a) The first-order Vibration mode

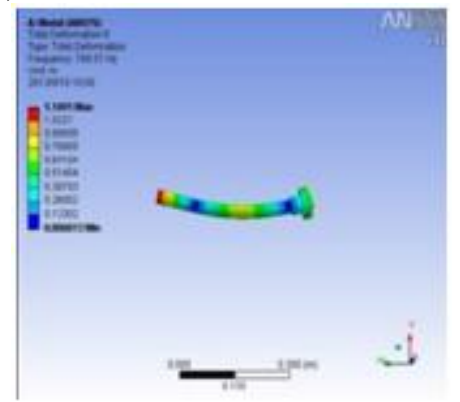

(b) The second -order Vibration mode

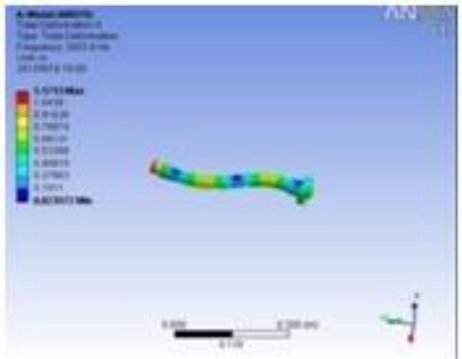

(c) The third -order Vibration mode



(d) The fourth -order Vibration mode

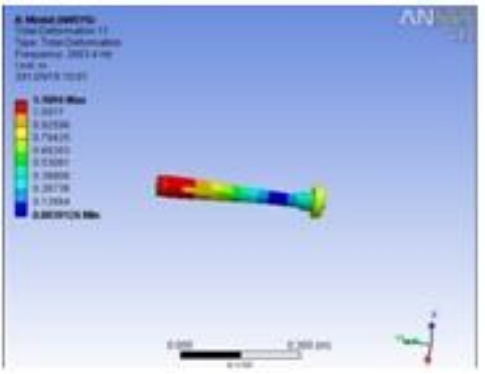

(e) The fifth-order Vibration mode

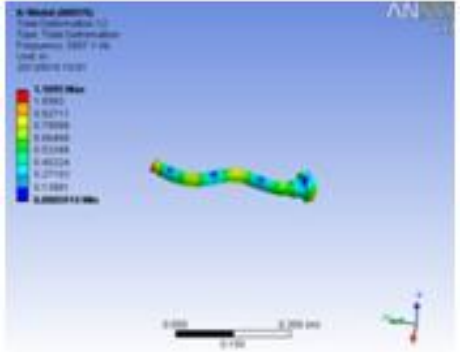

(f)The sixth-order Vibration mode

Figure 2: Spindle vibration modes

As observed in figure 2, the description of each order of the spindle modal is shown in table 2 .

Table 2: Spindle Each Order Vibration Description

\begin{tabular}{|c|c|}
\hline Order & Modal descriptions \\
\hline 1 & The maximum value for front end bending vibration \\
\hline 2 & $\begin{array}{c}\text { Frequencies and mode shapes are consistent with the first } \\
\text { order, which is actually two modal for the same modal. }\end{array}$ \\
\hline 3 & Maximum bending vibration is in the middle of the spindle \\
\hline 4 & The same modal to the third stage \\
\hline 5 & Torsional deformation of the spindle \\
\hline 6 & Bending vibration at the middle of the spindle \\
\hline
\end{tabular}

\section{Spindle Dynamic Optimization}

Future machine tools have to be highly dynamic system to sustain the required productivity, accuracy and reliability. Both the machine tool system and the spindle system are necessary to be optimized for their usability or cutting performance to meet the productivity and availability requirements of the end user. The structural dynamic modification theory shows that spindle dynamic optimization function can be set to increase the natural frequency of the spindle. According to the results of modal analysis, the following recommendation of structural modifications can be made:

(1) Improve the front end of the spindle support stiffness to reduce the first and the second order distortion.

(2) Increasing the spindle bending stiffness and torsional rigidity to reduce $3,4,5$, and 6 -order distortion.

The specific optimization methods are:

(1) Improve the support stiffness rigidity of the spindle bearings, selection of high bearing supporting stiffness, increase fluid viscosity, reduce the pressure of bearing clearance and increase oil supply. In addition, it can be increased by improving the precision of the spindle by making smooth contact area between the bearing and the spindle.

(2) By modifying the diameter of the spindle, it is possible to increase the spindle bending and torsion ability.

(3) By modifying the bearing support position, it is possible to improve the bending and torsional ability of the spindle. 


\section{Spindle Structure Dynamic Modification}

\subsection{Structural dynamic modification based on improved support stiffness}

In ANSYS work bench, selecting the spring damping unit, in the finite element model of the spindle bearing support position can add different stiffness constraints. The stiffness method is as shown in figure 3.



Figure 3: Main constrains, add spring damper unit

Through calculation, the supporting stiffness that will use in the spindle system, the first six natural frequencies is illustrated in Table 3.

Table 3: Support Stiffness to the influence of natural frequency

\begin{tabular}{|c|c|c|c|c|c|c|}
\hline$k \times 10^{7}$ & 1 & 2 & 3 & 4 & 5 & 6 \\
\hline 0 & 724 & 789 & 2053 & 2201 & 2603 & 3957 \\
\hline 2.5 & 810 & 866 & 2132 & 2300 & 2845 & 4100 \\
\hline 3.2 & 852 & 912 & 2198 & 2358 & 3015 & 4198 \\
\hline 4.8 & 926 & 1008 & 2285 & 2455 & 3900 & 4308 \\
\hline 5.7 & 1002 & 1152 & 2390 & 2650 & 4189 & 4485 \\
\hline
\end{tabular}

Compared with the original structure of prior to increase support stiffness, as each order natural frequencies were increased, the dynamic performance improved significantly.

\subsection{Spindle diameter structural dynamic modification}

From the material theory, increasing the shaft diameter can improve the bending and torsion ability of spindle and the system natural frequency. Since the need to assemble the spindle in the spindle bore, the hole size is limited by the spindle, the diameter can be modified in the range of $+5 \mathrm{~mm}$, $+8 \mathrm{~mm}$, $+11 \mathrm{~mm}$, and $+15 \mathrm{~mm}$. The calculated results of the natural frequency are shown in table 4.

Table 4: Modified natural frequency of the spindle diameter

\begin{tabular}{|c|c|c|c|c|c|c|}
\hline$D$ & 1 & 2 & 3 & 4 & 5 & 6 \\
\hline+5 & 1115 & 1296 & 2420 & 2698 & 4215 & 4458 \\
\hline+8 & 1175 & 1362 & 2500 & 2716 & 4325 & 4489 \\
\hline+11 & 1252 & 1423 & 2555 & 3210 & 4398 & 5001 \\
\hline+15 & 1308 & 1504 & 2754 & 3451 & 4448 & 5126 \\
\hline
\end{tabular}

Through different spindle diameter modified calculation, the system natural frequency increases along with the spindle diameter. Therefore, the improvement of system dynamic characteristics can be obtained by increasing the diameter of the spindle.

\subsection{Structural Dynamics Modification Of Bearing Support Position}

From material mechanics knowledge, a reasonable choice of supporting span can be increased to improve the spindle bending, torsional ability and natural frequency. In addition, shorten the length of the spindle overhanging, to reduce the deflection and amplitude response, is also very significant. Constrained by structural design, front spindle bearing supporting point can be adjusted in the range of $5 \mathrm{~mm} \sim$ $5 \mathrm{~mm}$, rear spindle bearing supporting point can be adjusted in the range of $40 \mathrm{~mm} \sim-40 \mathrm{~mm}$. Design of 5 kinds of bearing position adjustment schemes are as follows;

Scenario 1 front support relocation of $5 \mathrm{~mm}$; Scenario 2 after shifting support within $20 \mathrm{~mm}$; Scenario 3 after shifting support within $40 \mathrm{~mm}$; Scenario 4 rear support relocation $400 \mathrm{~m}$;

Scenario 5 support shifted within $25 \mathrm{~mm}$, front support move $5 \mathrm{~mm}$.

Table 5: Five kinds of changes in the natural frequency

\begin{tabular}{|c|c|c|c|c|c|c|}
\hline & 1 & 2 & 3 & 4 & 5 & 6 \\
\hline 1 & 755 & 810 & 2115 & 2278 & 2698 & 4201 \\
\hline 2 & 798 & 854 & 2193 & 2304 & 2750 & 4300 \\
\hline 3 & 842 & 924 & 2265 & 2382 & 2842 & 4365 \\
\hline 4 & 692 & 755 & 2054 & 2158 & 2563 & 4126 \\
\hline 5 & 832 & 8852 & 2236 & 2352 & 2782 & 4356 \\
\hline
\end{tabular}

Table 6: Wheel spindle front-end vibration amplitude

\begin{tabular}{|c|c|c|c|c|c|c|}
\hline & 1 & 2 & 3 & 4 & 5 & 6 \\
\hline 1 & 32 & 50 & 35 & 38 & 40 & 36 \\
\hline 2 & 40 & 52 & 40 & 40 & 45 & 42 \\
\hline 3 & 35 & 33 & 37 & 35 & 40 & 38 \\
\hline 4 & 28 & 29 & 30 & 33 & 40 & 32 \\
\hline 5 & 22 & 25 & 27 & 30 & 32 & 29 \\
\hline
\end{tabular}

As we observed from the natural frequency of the modified conditions:

Scenario 1 front support relocation, increasing supporting point spacing, natural frequency is reduced; scenario 2 after supporting displaced, reduced anchor spacing, natural frequency increases; scenario 3 after supporting displaced, the supporting point spacing is further reduced a small than option 2, natural frequency of program is greater than 2; Scenario 4 after relocation of the supporting point, further increase supporting point spacing than option 1, natural frequency is smaller than scheme 1; Scenario 5 front support point shift, after supporting displaced, option 2 is slightly larger than the natural frequency.

Looking at from the end of amplitude response:

Scenario 1 front support relocation, front amplitude decreases; scenario 2 after supporting displaced, front spindle amplitude increases; scenario 3 after supporting displaced, the greater the amplitude of the front end of the spindle; scenario 4 after support relocation, front spindle amplitude decreases; Scenario 5 after you move the support, before supporting displaced, front spindle end amplitude is minimum. 


\section{International Journal of Science and Research (IJSR) \\ ISSN (Online): 2319-7064}

Index Copernicus Value (2013): 6.14 | Impact Factor (2014): 5.611

Based on comprehensive evaluation of natural frequencies and mode shapes of amplitude, plan of 5 for the five structural modifications is of the optimal modification.

\section{Conclusion}

Based on the computer numerical control (CNC) machine tool structure as the research objective, the spindle is molded using ANSYS Work bench for dynamic performance analysis. The bearing support stiffness, mode shapes, frequency response function at any point on the spindle has been analyzed. The dynamic deflections along the spindle shaft as well as contact force on the bearing have been tested. Also the effects of relocation of the bearing support position, the influence of change in spindle shaft diameter to a certain limit of range on the dynamic performance, and weak points on the machine tool spindle structure have been analyzed. According to the result of the modal analysis, structural dynamic optimization methods have been pointed out. The spacing of the bearings are optimized to achieve either maximum dynamics stiffness or maximum chatter free depth of cut at the desired speed region for a given cutter geometry and work-piece material. It is possible to add constraints to model mounting of the spindle on the machine tool. The weak parts of the structure have been optimized. Moreover, the establishments of a three-dimensional geometric model of the machine tool spindle through the way of free meshing adopt; reasonable finite element model is established.

\section{References}

[1] E.K. Wang, M.Jagfeld, Sub structuring for large structures Using Finite Element Program ANSYS on a Work Station, In: C. T. LEONDES, Editor(s), Control and Dynamic System, Academic Press, 1993, Volume 59, Part 2, Pages 137-166

[2] Minli Yu, NingSheng Feng, Eric J Hahn, Experimental evaluation of a modal parameter based on system identification procedure, Mechanical systems and Signal Processing, Volumes 68-69, February 2016, pages 302315

[3] Chen.C.K., Tsao, Y.K., 2006.A stability analysis of regenerative chatter in turning process without using tailstock, International Journal of Advanced Manufacturing and Technology, 29, pp.648-54.

[4] Chiou.Y.S., Chung.E.S, Liang. S. Y., 1995, Analysis of tool wears effect on chatter stability in turning, International Journal of Mechanical Sciences, 37(4), pp.391-40.

[5] Wei Dou, Xiaocong He, Modal Analysis of Machine Tool Spindle under Uncertainty, Faculty of Mechanical and Electrical Engineering, Kunming University of Science and technology, Kunming, 650500, China

[6] MARIN DOINA, Modal analysis applied to milling machine, Robotics and Mechatronics Department Institute of Solid Mechanics of the Romanian Academy 15, Constantin Mille Street, Bucharest, 010141 ROMANIA

[7] Miron Zapciu, Caudiu F. Bisu, Jean-Yves K'nevez, Expermental study of machining system:dynamic characterization, University Politechnica from Bucharest, 313 Splaiu Independenti, 060042 Bucharest, Romania

[8] Anu Maria, Introduction to Modeling and Simulation,
State University of New York at Binghamton Department of Systems Science and Industrial Engineering Binghamton, NY 1390-6000, U.S.A 